\title{
Conjunctival Melanoma at the Site of Previous Ocular Injury
}

Widad Belaydi", E. Abdallah, K. Amhoud, A.Lalaoui, B. Marzouqi, K. Amhoud, S. Karmoun, F. Kettani, A. Berraho.

Department of Ophtalmology, Ibn Sina Hospital, University Mohamed V, Rabat, Morocco

DOI: $10.36347 /$ sjams.2020.v08i09.032

| Received: 07.09.2020 | Accepted: 15.09.2020 | Published: 24.09.2020

*Corresponding author: Dr. BELAYDI Widad

Abstract

Case Report

Conjunctival melanoma is relatively rare aggressive malignant tumor. Its incidence in the white population is estimated at 0.2 to 0.8 per million. Its management consists on surgical excision, cryotherapy, and eventually radiotherapy or local chemotherapy. UV rays are largely incriminated in the pathogenesis of melanoma, while the role of trauma is still a subject of controversy; this hypothesis of trauma is reinforced by the presence of melanomas in areas with low exposure to sunlight. We report a case of conjunctival melanoma evolving at the site of previous ocular trauma.

Keywords: Melanoma, Conjunctiva, Ocular injury.

Copyright @ 2020: This is an open-access article distributed under the terms of the Creative Commons Attribution license which permits unrestricted use, distribution, and reproduction in any medium for non-commercial use (NonCommercial, or CC-BY-NC) provided the original author and source are credited.

\section{INTRODUCTION}

Conjunctival melanoma is a relatively rare malignant tumor. Its incidence in the white population is estimated at 0.2 to 0.8 per million [1]. Melanoma is considered to be a multifactorial disease. Exposure to ultraviolet (UV) rays is the most recognized and potentially modifiable risk factor of developing malignant melanomas because of its genotoxic effect [2]. The role of trauma in the pathophysiology of melanomas is also discussed in the literature.

\section{ObSERVATion}

A 54-year-old man with a history of perforating ocular trauma caused by a wooden stick 20 years ago, occasioning a conjunctivo-scleral wound in the superior-nasal quadrant of the right eye, the wound was sutured without any complications. Recently he was referred for a conjunctival lesion that had been evolving for 4 months.

The ophthalmological examination found a pigmented mass in the bulbar-nasal conjunctiva of the right eye, according to the patient, this lesion develop at the same site of the previous ocular trauma. This lesion is pedicled, extending from the caruncle to the limbus. It has a polylobulated appearance, and richly vascularized with soft consistency (Figure 1). The temporal area of the eye is normal; particularly no primary acquired melanosis in the sclera. CT scan of the orbital region shows no intraocular extension.
Considering the strongly malignant aspect a complete resection was performed. The procedure is completed by the cryo-application of the excision bed. Chemotherapy based on mitomycin $\mathrm{C}$ was administered because of the large extent of the lesion (Figure 2).

The histological examination $\begin{array}{r}\text { revealed a } \\ \text { malignant melanoma }\end{array}$
conjunctival
$0.7 \times 0.4 \times 0.3 \mathrm{~cm}$ (Figure3). Radiological assessment of
extraocular extension has returned to normal. The
evolution is favourable with a 2-year follow-up.

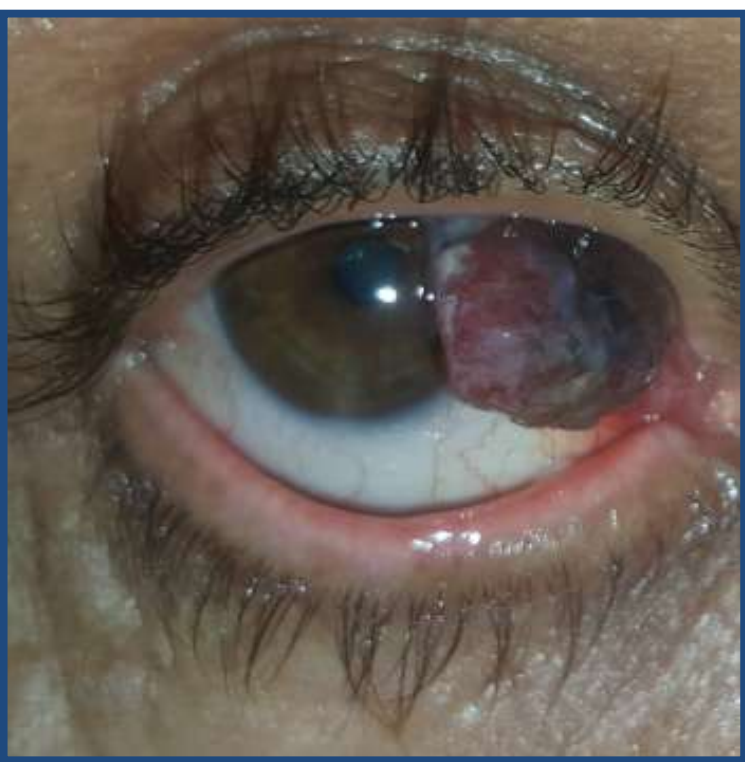

Fig-1: Nodular conjunctival malignant melanoma in the upper nasal quadrant of the bulbar conjunctiva 


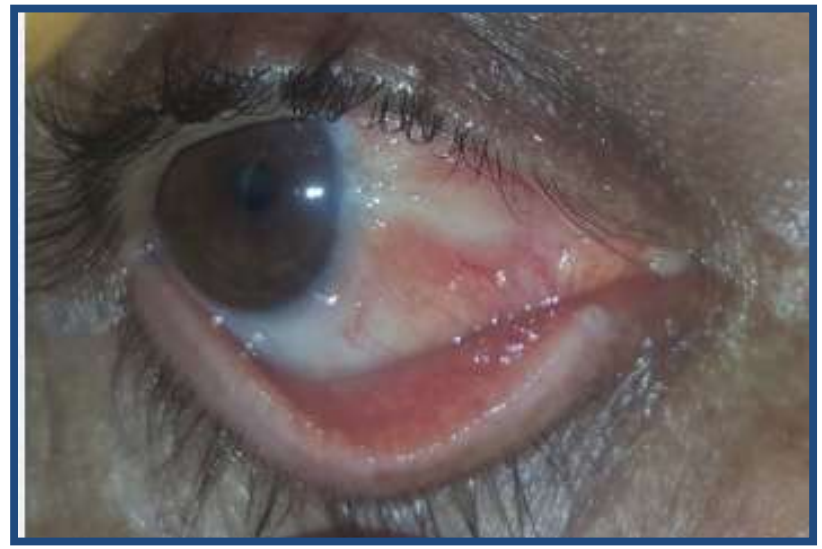

Fig-2: The appearance after surgical resection

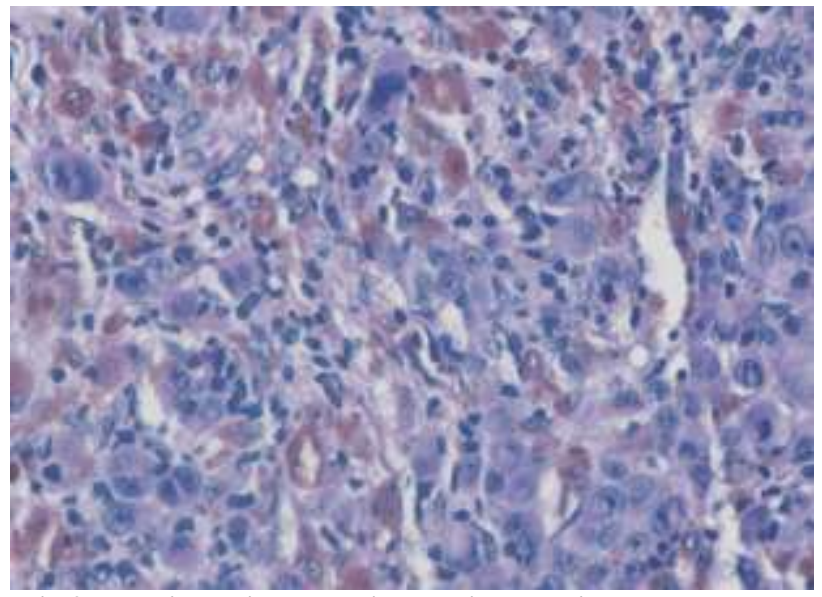

Fig-3: The histological analysis revealing a malignant melanoma

\section{DISCUSSION}

Conjunctival malignant melanoma accounts for only $5 \%$ of melanomas in the ocular region [3]. This cancer generally develops from a primary acquired melanosis in 53\%, which is characterized in pathological anatomy by an abnormal proliferation of melanocytes in the conjunctival or corneal epithelium without reaching the basement membrane or the chorion, on a pre-existing nevus in $4 \%$, or de novo in $37 \%$ [4]. It is an aggressive tumor with a metastasis rate approximately $32 \%$ at 15 years [5]. Its management consists on surgical excision using the "no touch" technique, followed by cryotherapy of the excision bed [6]. Adjuvant treatment may be combined with radiotherapy or local chemotherapy, notably mitomycin C [7].

Melanoma results from the interaction between genetic sensitivity and environmental exposure [2]. UV rays are largely incriminated in the pathogenesis of melanoma, while the role of trauma is still a subject of controversy. However, it is an accepted risk factor for squamous cell carcinomas [8]. This hypothesis of trauma is reinforced by the presence of melanomas in areas with low exposure to sunlight, notably acral melanoma, where mechanical stress is suggested in the literature [9-11] knowing that melanoma of the feet is more frequent than melanoma of the hands [12].
Some observations in the literature of "posttraumatic" ocular melanoma have also been reported [13-15]. This observation also illustrates an unusual association of a tumour 500 times less rare than skin melanoma : [1] conjunctival melanoma at the site of an old trauma. Waiting for an epidemiological study with sufficient numbers to decide on this possible risk factor.

\section{CONCLUSION}

This observation and review of the literature suggests the role of trauma in the occurrence of melanomas, prompting the ophthalmologist to be mindful of an eventual transformation of an old ocular scar for early management.

\section{REFERENCES}

1. Brownstein S. Malignant Melanoma of the Conjunctiva . Cancer Control. September/October. 2004, 11(5).

2. Rastrelli M, Tropea S, Rossi CR, Alaibac M. Melanoma: epidemiology, risk factors, pathogenesis, diagnosis and classification. In vivo. 2014 Nov 1;28(6):1005-11.

3. Rajbhandari Y, Gupta S, Yadav R, Manandhar A, Mon AM, Joshi P, Shrestha GB. A rare case of conjunctival malignant melanoma with orbital invasion. Nepalese Journal of Ophthalmology. 2019 Sep 2;11(1):77-81.

4. Shields CL, Markowitz JS, Belinsky I, Schwartzstein H, George NS, Lally SE, Mashayekhi A, Shields JA. Conjunctival melanoma: outcomes based on tumor origin in 382 consecutive cases. Ophthalmology. 2011 Feb 1;118(2):389-95.

5. Shields CL, Shields JA, Gündüz K, Cater J, Mercado GV, Gross N, Lally B. Conjunctival melanoma: risk factors for recurrence, exenteration, metastasis, and death in 150 consecutive patients. Archives of Ophthalmology. 2000 Nov 1;118(11):1497-507.

6. Vora GK, Demirci H, Marr B, Mruthyunjaya P. Advances in the management of conjunctival melanoma. Survey of ophthalmology. 2017 Jan 1;62(1):26-42.

7. Cohen VM, O'Day RF. Management Issues in Conjunctival Tumours: Conjunctival Melanoma and Primary Acquired Melanosis. Ophthalmology and Therapy. 2019 Dec 1;8(4):501-10.

8. Kowal-Vern A, Criswell BK. Burn scar neoplasms: a literature review and statistical analysis. Burns. 2005 Jun 1;31(4):403-13.

9. O'Toole EA, Stephens R, Young MM, Tanner A, Barnes L. Subungual melanoma: a relation to direct injury?. Journal of the American Academy of Dermatology. 1995 Sep 1;33(3):525-8.

10. Möhrle M, Häfner HM. Is subungual melanoma related to trauma?. Dermatology. 2002;204(4):25961. 
11. Bormann G, Marsch WC, Haerting J, Helmbold P. Concomitant traumas influence prognosis in melanomas of the nail apparatus. British Journal of Dermatology. $2006 \mathrm{Jul} ; 155(1): 76-80$.

12. Lesage C, Journet-Tollhupp J, Bernard P, Grange F. Mélanome acral post-traumatique: une réalité sous-estimée?. InAnnales de dermatologie et de vénéréologie 2012 139(11): 727-731). Elsevier Masson.

13. El Baba F, Blumenkranz M. Malignant melanoma at the site of penetrating ocular trauma. Archives of Ophthalmology. 1986 Mar 1;104(3):405-9.
14. Naseri A, Char DH, Howes E, Paglen P. Amelanotic corneal melanoma after a blast injury. American journal of ophthalmology. 2001 Feb $1 ; 131(2): 259-60$.

15. Jukić T, Katusic D, Kordić R, Cacić M, Braunschweig T, Thumann G. Malignant melanoma of the cornea after blunt trauma. Der Ophthalmologe: Zeitschrift Der Deutschen Ophthalmologischen Gesellschaft. 2009 Jul;106(7):625-7. 